\title{
Polymer optical fiber bragg grating sensors measuring acceleration
}

Stefani, Alessio; Yuan, Scott Wu; Andresen, Søren; Bang, Ole

Published in:

Proceedings of the Australian Conference on Optical Fibre Technology

Publication date:

2010

Document Version

Peer reviewed version

Link back to DTU Orbit

Citation (APA):

Stefani, A., Yuan, S. W., Andresen, S., \& Bang, O. (2010). Polymer optical fiber bragg grating sensors: measuring acceleration. In Proceedings of the Australian Conference on Optical Fibre Technology

\section{General rights}

Copyright and moral rights for the publications made accessible in the public portal are retained by the authors and/or other copyright owners and it is a condition of accessing publications that users recognise and abide by the legal requirements associated with these rights.

- Users may download and print one copy of any publication from the public portal for the purpose of private study or research.

- You may not further distribute the material or use it for any profit-making activity or commercial gain

- You may freely distribute the URL identifying the publication in the public portal

If you believe that this document breaches copyright please contact us providing details, and we will remove access to the work immediately and investigate your claim. 


\title{
Polymer Optical Fiber Bragg Grating Sensors: Measuring Acceleration
}

\author{
Alessio Stefani ${ }^{1}$, Wu Yuan ${ }^{1}$, Søren Andresen ${ }^{2}$, and Ole Bang ${ }^{1}$ \\ ${ }^{1}$ Technical University of Denmark, DTU Fotonik, Department of Photonic Engineering, 2800 Kgs.Lyngby, Denmark \\ ${ }^{2}$ Brüel \& Kjær Sound and Vibration Measurements A/S, 2850 Nærum, Denmark
}

\section{Abstract Summary}

Fiber-optical accelerometers based on polymer optical fiber Bragg gratings are reported. We have written fiber Bragg gratings for $1550 \mathrm{~nm}$ and $850 \mathrm{~nm}$ operations, characterized their temperature and strain response, and tested their performance in a prototype accelerometer. grating

Polymer optical fiber; accelerometer; fiber sensor; fiber Bragg

\section{INTRODUCTION}

Fiber Bragg grating (FBG) sensors have attracted a lot of attention in the last decade because of their performances, size and multiplexing capability [1-3]. Here we focus on fiber optical accelerometer based on FBGs [4]. An important target in developing sensors is to improve more and more the sensitivity. Polymer fiber-based sensors are well suited for this purpose. In fact their low Young's modulus, compared to that of silica fibers, makes this particular kind of fiber able to give a bigger response to smaller variations [5].

We here present polymer optical fiber Bragg gratings (POF FBG) and their use into an accelerometer prototype, where a shorter length of fiber increases the dynamic range and the sensitivity and overcomes the biggest problem of polymer fibers: the loss [5].

\section{POLYMER FIBER BRAGG GRATINGS}

The gratings have been written by using the phase-mask technique and by using a $30 \mathrm{~mW} 325 \mathrm{~nm} \mathrm{CW} \mathrm{HeCd} \mathrm{laser}$ (IK5751I-G, Kimmon), whose beam has been expanded to 1.2 $\mathrm{cm}$ with a cylindrical lens along the direction of the fiber axis and focused with a second cylindrical lens into the core of the POF in the orthogonal direction. The pattern imprinted into the fiber was determined by the phase mask (Ibsen Photonics), placed just above the fiber. The fiber used is a commercial step index POF made of PMMA, which has a polystyrene doped PMMA core (MORPOF02, Paradigm Optics). The characterization has been made by measuring the reflection of the grating using a circulator. The first arm of the circulator was connected to a SuperK Versa broadband source (NKT Photonics). The broadband signal was then butt-coupled to the
POF from the second arm of the circulator. The reflection was collected and measured at the third arm of the circulator with an Optical Spectrum Analyzer (Ando AQ6317B).

\section{A. Bragg grating with resonance wavelength of $1550 \mathrm{~nm}$}

At first a grating with a resonance wavelength of $1550 \mathrm{~nm}$ was written because of the possibility of using components well developed for the fiber optics communication industry. A phase mask with 1048.7.nm period from Ibsen Photonics was used. A spectrum of the grating is shown in Figure 1.

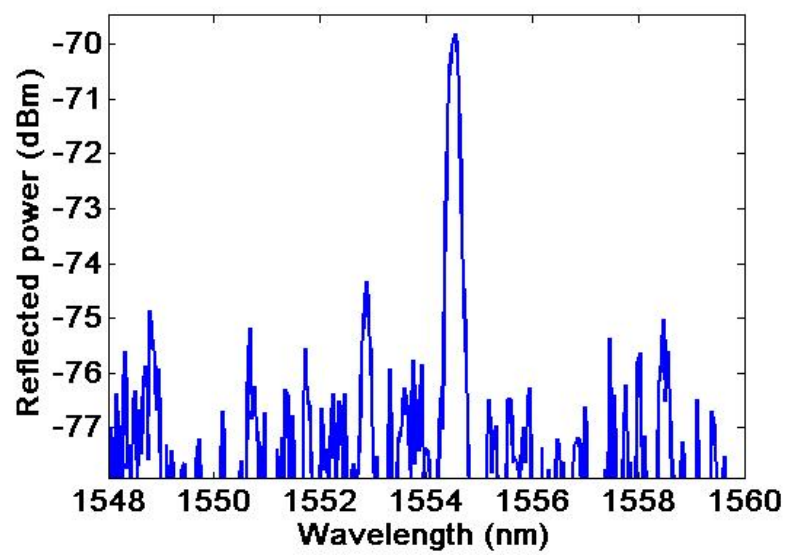

Figure 1. Reflection spectrum of a POF FBG with a resonance wavelength of $1550 \mathrm{~nm}$. The spectrum is measured after one hour writing time.

\section{B. Bragg grating with resonance wavelength of $850 \mathrm{~nm}$}

A considerable decrease in PMMA material loss from about $100 \mathrm{~dB} / \mathrm{m}$ to below $1 \mathrm{~dB} / \mathrm{m}$ can be achieved by working at a lower wavelength [5]. In particular this target can be reached at an operation wavelength of $850 \mathrm{~nm}$. It is also convenient to work at this particular wavelength since the CMOS technology potentially can provide devices that are cheaper than those at $1550 \mathrm{~nm}$. For these reasons there is currently a strong push in the sensor and interrogator industry to develop devices at $850 \mathrm{~nm}$.

We have therefore also written POF FBGs have been realized with a resonance wavelength of $850 \mathrm{~nm}$ using a phase mask with a period of $572.4 \mathrm{~nm}$ (Ibsen Photonics). A spectrum of this grating is shown in 
Figure 2.

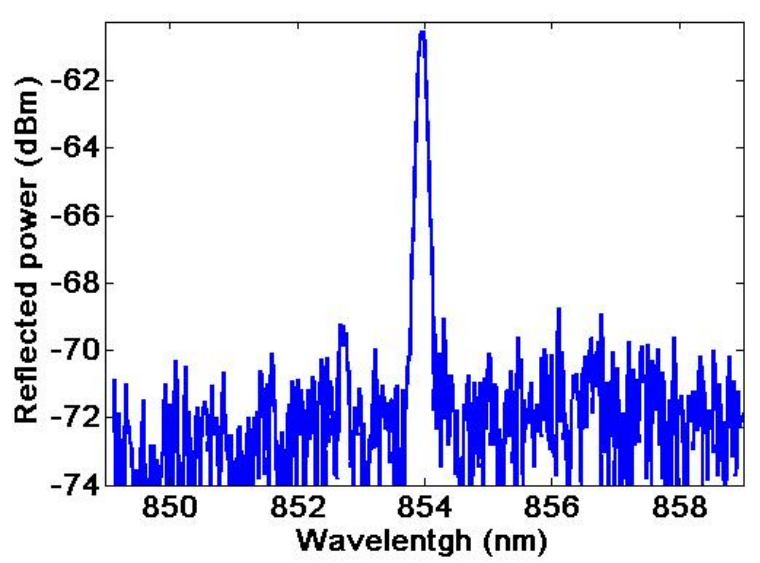

Figure 2. Reflection spectrum of a POF FBG with a resonance wavelength of $850 \mathrm{~nm}$. The spectrum is measured after one hour writing time.

\section{GRATINGS CHARACTERIZATION}

The gratings have been characterized in terms of static strain and temperature response.

\section{A. Strain}

The wavelength shift as function of the applied static strain, also known as strain sensitivity, has been measured for the gratings at both $1550 \mathrm{~nm}$ and $850 \mathrm{~nm}$. The results are shown in

Figure 3. As anticipated both responses are linear and that the strain sensitivity for the grating at $850 \mathrm{~nm}$ is lower than the one for the grating at $1550 \mathrm{~nm}$. This difference is due to geometrical considerations, for which the same change in fiber length produce a shift proportional to the resonance wavelength [2]. The sensitivity for the $1550 \mathrm{~nm}$ grating has been measured to be $1.3 \mathrm{pm} / \mu \varepsilon$ while for the $850 \mathrm{~nm}$ grating it is $0.71 \mathrm{pm} / \mu \varepsilon$.

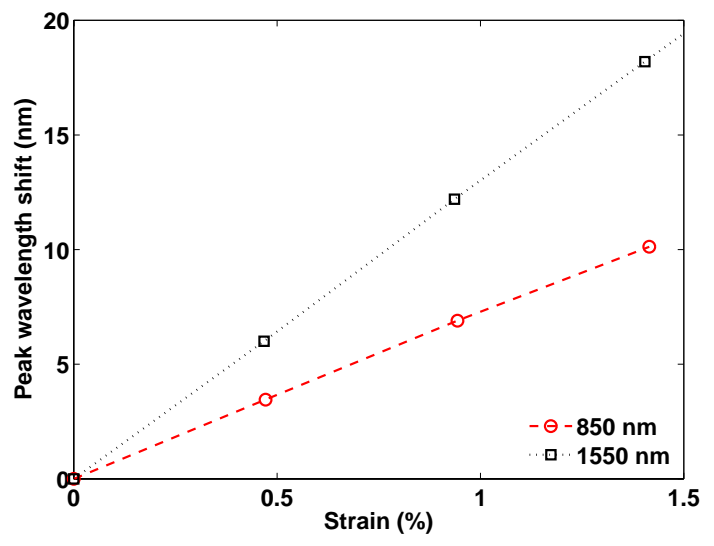

Figure 3. Static strain sensitivity characterization of $1550 \mathrm{~nm}$ and $850 \mathrm{~nm}$ POF FBG.

\section{B. Temperature}

The grating's temperature response has also been investigated. In particular a comparison between gratings in annealed and not annealed fiber has been done.

The results (Figure 4) show how annealing can improve the operational range with no hysteresis of the grating in this commercial POF with about $20^{\circ} \mathrm{C}$ and avoid a peak power decrease at high temperature [6].
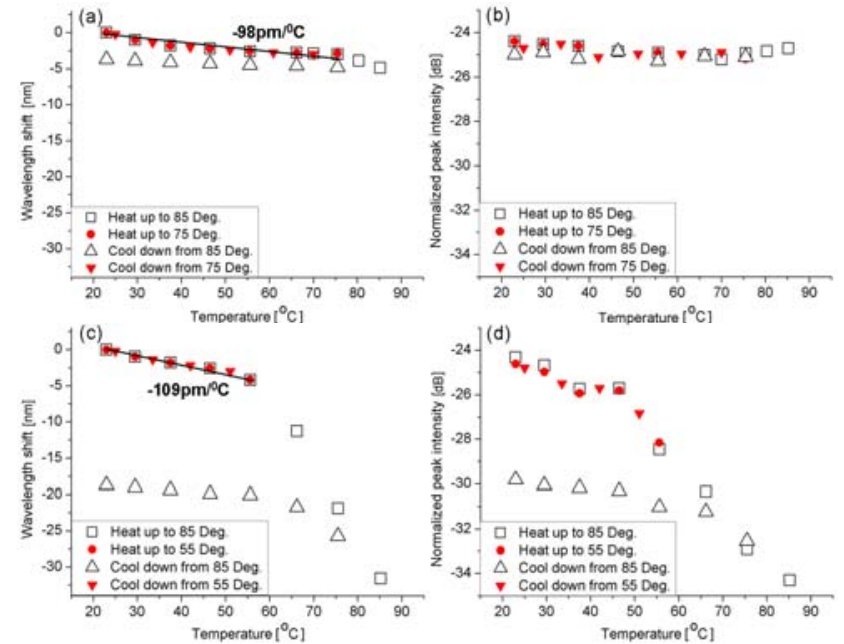

Figure 4. Temperature Characterization of $1550 \mathrm{~nm}$ Bragg grating. Bragg wavelength shift and peak intensity variation with temperature for two consecutive heating and cooling cycles in the annealed POF (a-b) and the nonannealed POF (c-d). The temperature response of the Bragg wavelength in (a) and (c) show an approximately linear thermal sensitivity of $-98 \mathrm{pm} /{ }^{\circ} \mathrm{C}$ and $109 \mathrm{pm} /{ }^{\circ} \mathrm{C}$ for the annealed and non-annealed POF, respectively.

IV.

POF FBG BASED ACCELEROMETER

The basic idea on which the optical accelerometer is based is shown in

Figure 5. The acceleration is converted into strain by a mechanical transducer. The transducer is made so that the strain on the fiber is linearly dependent from acceleration. In this way the simple measurement of the Bragg wavelength shift correspond to a measurement of acceleration. This configuration is useful when more than one sensor want to be placed along the same fiber.

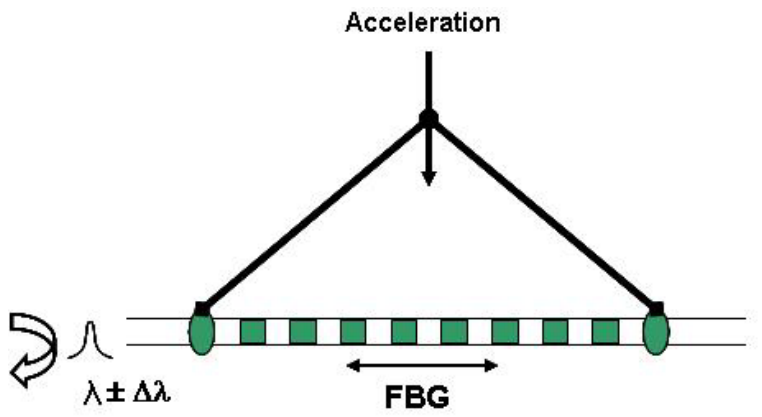

Figure 5. FBG-based accelerometer schematic. 
The frequency response of the accelerometer has been measured for different accelerations. In Figure 6 we show the frequency response normalized to the applied acceleration when $0.5 \mathrm{~g}$ acceleration was applied. The accelerometer shows a flat response for frequencies up to more than $1 \mathrm{kHz}$. The sensitivity of the accelerometer is $20 \mathrm{pm} / \mathrm{g}$ and the system resonance frequency is $2.95 \mathrm{kHz}$.

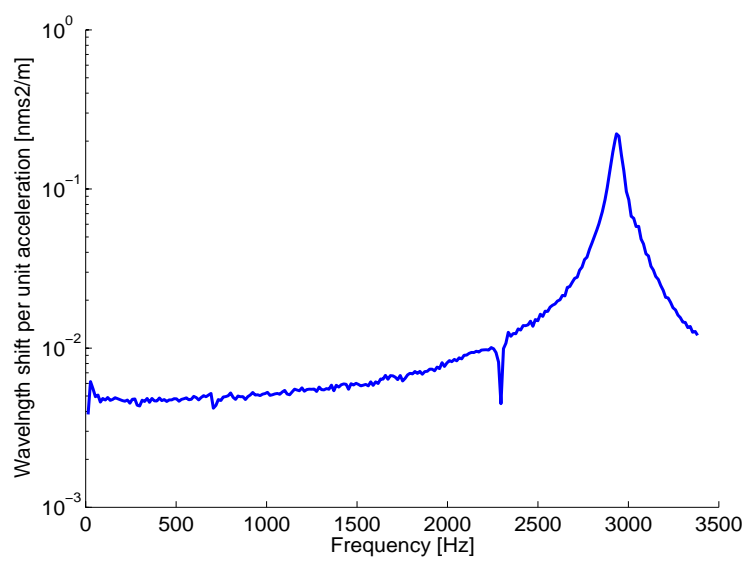

Figure 6. Frequency response of the POF FBG-based accelerometer when 0.5 $\mathrm{g}$ acceleration is applied.

In order to test the operational range of the accelerometer, the response to a sine wave with a frequency of $160 \mathrm{~Hz}$ with different accelerations has been measured. The acceleration span was from $1 \mathrm{~g}$ to $15 \mathrm{~g}$. The results are shown in Figure 7. The accelerometer has a linear behavior up to $4.5 \mathrm{~g}$ and from 5 to $15 \mathrm{~g}$. The discontinuity region in between the linear ones is at the moment under investigations.

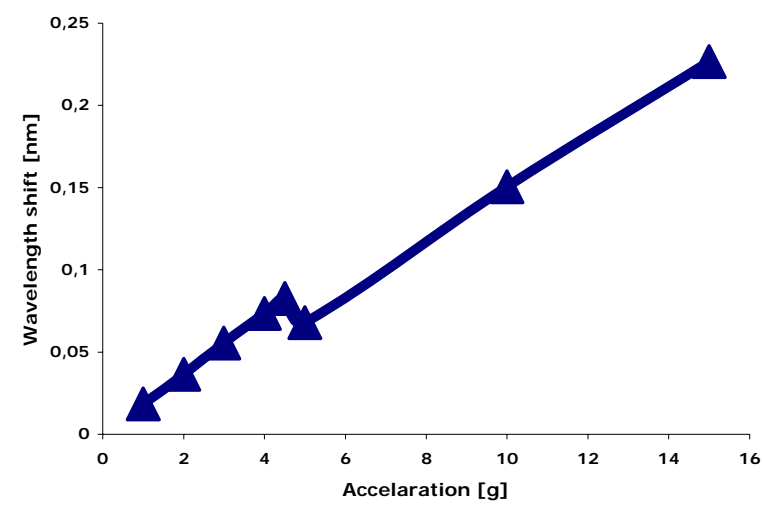

Figure 7. Acceleration measurements when a $160 \mathrm{~Hz}$ sine wave is used for excitation.

At last, a comparison of the frequency response of the accelerometer using a silica FBG with the one using the POF FBG have been done. In Figure 8 it is possible to see that the sensitivity of the POF FBG-based accelerometer is higher than the silica FBG-based one. It is possible to notice also that the resonance frequency shifts to a lower frequency when using a polymer fiber. This is due to the reduced stiffness of the whole system. In order to compare the two accelerometers including both parameters (sensitivity and resonance frequency) the product of sensitivity and resonance frequency square is used as figure of merit. The result is that for the POF FBG-based accelerometer this figure of merit is almost twice the one for the silica FBG-based accelerometer. In fact the figure of merit for the POF FBG accelerometer is $174.05 \mathrm{pm} \mathrm{kHz}^{2} / \mathrm{g}$ while the one for the silica sensor is $92.05 \mathrm{pm} \mathrm{kHz}^{2} / \mathrm{g}$.

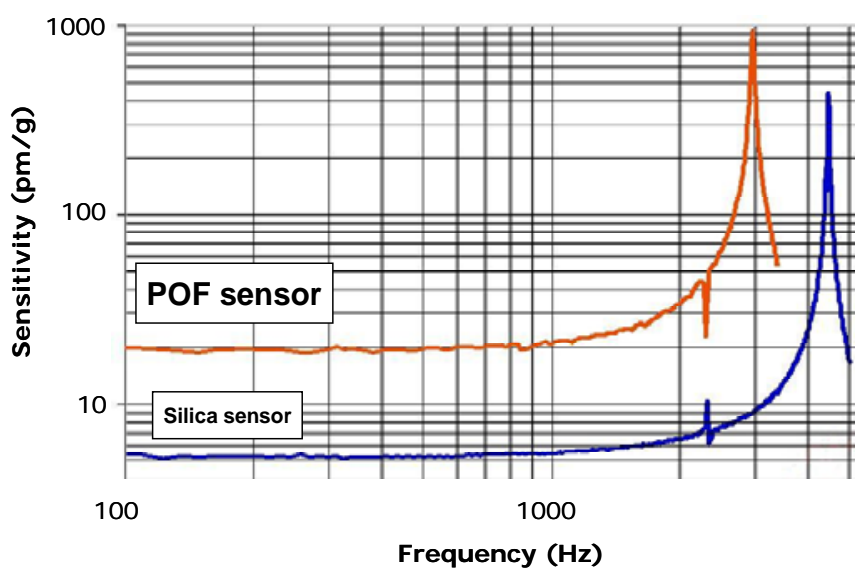

Figure 8. Frequency response of the accelerometer with POF FBG and silica FBG.

\section{CONCLUSIONS}

In conclusion polymer optical fiber Bragg gratings with resonance wavelength of $1550 \mathrm{~nm}$ and $850 \mathrm{~nm}$ have been produced and characterized. Moreover, improved performance and stability has been demonstrated by using annealed fibers. The gratings have then been used in an optical accelerometer. The accelerometer showed a flat frequency response up to frequencies higher than $1 \mathrm{kHz}$, a resonance frequency of about $3 \mathrm{kHz}$ and a linear sensitivity of $20 \mathrm{pm} / \mathrm{g}$ up to accelerations of $4.5 \mathrm{~g}$. A comparison of the same accelerometer with a silica FBG showed almost a doubling of the figure of merit sensitivity time resonance frequency square achieving an increase from $92.05 \mathrm{pm} \mathrm{kHz}^{2} / \mathrm{g}$ to $174.05 \mathrm{pm} \mathrm{kHz}^{2} / \mathrm{g}$.

\section{ACKNOWLEDGMENT}

We would like to acknowledge support from the Danish National Advanced Technology Foundation.

\section{REFERENCES}

[1] Shizhuo Yin, Paul B. Ruffin, Francis T.S. Yu, Fiber Optic Sensors, 2nd ed., CRC Press, 2008, pp 109-162.

[2] D. Webb and K. Kalli, "Recent Advancements, Industrial Applications and Market Exploitation",in Fiber Bragg Grating Sensors, A. Cusano, A. Cutolo, and J. Albert, eds. (Bentham Science Publishers Ltd, 2009), pp. $1-20$. 
[3] A.D. Kersey et al., "Fiber grating sensors", J. Lightwave Technol. 15, 1997, pp. 1442-1463.

[4] T. A. Berkoff, A.D. Kersey, "Experimental Demonstration of a Fiber Bragg Grating Accelerometer", IEEE Photon. Technol. Lett. 8, 1996, pp. 1677-1679.
[5] M.Large, L. Poladian, G. Barton, M.A. van Eijkelenborg, Microstructured Polymer Optical Fibres, Springer, 2008, pp. 1-15.

[6] W. Yuan et al., "Improved thermal and strain performance of annealed polymer optical fiber Bragg gratings", Opt. Commun., unpublished. 